\title{
Comparison and assessment of a different steel materials based on core losses reduction for three-phase induction motor
}

\author{
Yaser Atta Yassin, Ali Nasser Hussain, Nagham Yassin Ahmed
}

Middle Technical University, Electrical Engineering Technical College, Baghdad, Iraq

\begin{tabular}{l} 
Article Info \\
\hline Article history: \\
Received Jul 21, 2020 \\
Revised Jan 18, 2021 \\
Accepted Feb 2, 2021 \\
\hline
\end{tabular}

Keywords:

Ansys Maxwell

Core losses curve

Magnetization curve

Three phase induction motor

Three types of steel

\begin{abstract}
This paper presents a core losses and performance calculation with different type of steel materials in the core design for three-phase induction motor by using "ANSYS Maxwell" program in order to identify the core material that provides the most effective performance by iron losses reduction. The coefficients of core losses are calculated from the magnetization curve and core Loss curve based on the on steel material databases. Although the difficult to obtain because of the little of existing information. Results show the capability of the proposed Cobalt steel (Hiperco 50) to achieve the significant losses reduction in comparison to the Electrical Steel NGO-AK Steel's M-19 and Low Carbon Steel-SAE1020.
\end{abstract}

This is an open access article under the CC BY-SA license.

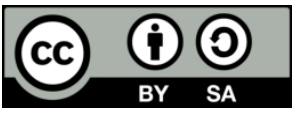

Corresponding Author:

Ali Nasser Hussain

Department of Electrical Power Engineering Techniques

Electrical Engineering Technical College

Middle Technical University, Baghdad, Iraq

Email: alinasser1974@yahoo.com

\section{INTRODUCTION}

During the recent years, the induction motors (IM) are utilized, instead of the DC motors, in many different applications including domestic and industrial uses such as heat pumps, wind generator, textile mills, machine tools, transposition, air conditioners, and robotics [1]-[4]. In order to make the induction motors operate, there is no need for sliding contacts or permanent magnets, which make them too simple and have low manufacturing cost [5]-[8]. With little exceptions, the electric motors are considered the major source of the mechanical energy supplies in industry. Along many years, induction motors were considered as the workhorse in industry. Most of these motors that used in industry are largely three-phase. However, in small power industries, single phase machines are so common [9]. Many types of induction machines are presented in the markets with various powers ranging from several watts up to megawatts.

Despite induction motors have easy design as compare to a DC motors, but it has low efficiency because of high losses. The reducing of iron losses is considered one of the main points that related for improving the performance and developing the future of these machines [10]. The determination of core losses and other losses in the electrical machines is one of the tasks that must be performed during the electromagnetic calculation.

Three phase induction motors are calculated by Ansoft RMxprt and tow dimension (transient mode) Application [11]. The reduction of iron losses in a three-phase induction motor is depend on the quality of magnetic materials that used. Therefore, for optimizing the design each type of steel materials contains a digital core loss curves (magnetization curve and permeability curve) [12]-[14]. 
The data of proposed steel material type that used in core can be added directly to the design of a three-phase induction motor program (ANSYS Maxwell). This program of simulation design will be able to speed up the time to see the effects of steel material type on the performance of the motor [15]. This paper proposed a three type of steel materials in the core design for three-phase induction motor to present a comprehensive comparison and assessment in order to identify the core material that provides the most effective performance by iron losses reduction.

\section{MOTOR CORE LOSSES CALCULATION}

The model of three phase induction motor is designed by ANSYS Maxwell software. Also, from this software is calculated the following Losses:

1. Stranded Loss (R-loss) in the windings of motor is determined by (1):

$$
P=3 I^{2} R
$$

where $I$ is the current and $R R$ is the phase resistance.

During 100 years ago, fertile minds - Steinmetz (1900), Bertotti (1990) and Ionel (2010) struggling to develop the models that can calculated core loss at any time. By matching the physics that based on the interpolation function with core loss data, a common Bertotti model of core loss is the sum of eddy current losses, hysteresis losses and additional losses [12].

2. Core Loss (Iron Loss)

The core losses of motor are classified to eddy current losses, hysteresis losses and additional losses as follow:

a. Eddy current losses (2)(3):

$$
\begin{aligned}
& P_{c}=K_{c}\left(f B_{m}\right)^{2} \\
& K_{c}=\pi^{2} \sigma^{2} \frac{d^{2}}{\delta}
\end{aligned}
$$

where $\left(K_{c}\right)$ is coefficient of eddy current losses, $(\delta)$ is the electrical conductivity and $(d)$ is steel sheet thickness.

b. Hysteresis losses (4):

$$
P_{h}=K_{h} f B_{m}{ }^{2}
$$

where: $\left(K_{h}\right)$ is coefficient of hysteresis losses, $(f)$ is the frequency and $\left(B_{m}\right)$ is the maximum value of magnetic induction.

c. Additional losses (5):

$$
P_{e}=K_{e}\left(f B_{m}\right)^{1.5}
$$

where $\left(K_{e}\right)$ is the coefficient of additional losses. The iron losses will be (6):

$$
P=P_{c}+P_{h}+P_{e}
$$

The Bertotti model expects all the coefficients of iron losses $K_{c}, K_{h}$ and $K_{e}$ to be positive. But if are positive, then core losses curve will be increased monotonically then the flux density B increases. The Bertotti model did not foresee to the point of inflection as similar to the core loss models. The steel is a major material that used in the manufacture of electrical motors in home appliances, industrial machinery and transportation [16-18]. Especially, it forms the basis of the motors and converts the magnetic energy with high efficient into electrical energy [10].

Both the magnetization curve $(B-H)$ and core Loss curve $(B-f)$ are require for looking them at the same time. In general, the higher efficiency is obtained when using types of steels with lower core losses [19]. Therefore, in order to achieve the higher efficiency requires the reducing the magnetic current while reducing the core loss [20]. The $(B-H)$ curve is measured by the manufacturer as locus of tips of a series of hysteresis loops. The slope of permeability is increased with $\mathrm{H}$ increasing as shown in (7):

$$
\bar{B}=d B /\left(\mu_{0} d H\right)
$$


where $(B)$ magnetic flux density, $(H)$ magnetic field intensity and $\mu_{0}$ permeability for free space.

It is known that the core losses vary according to the different of flow density and frequency [21]. But it is also known to differ with the manufacturer's specifications. Each company has its own formula and recipe for manufacturing. By comparing the characteristics of curves for core loss, it can help to discover the manufacturer material that produces the lowest loss with flow density and frequency.

Three types of steel were used, after hardly obtaining the $(B-H)$ curve and core losses curve for each of them separately and applied each of them to the three-phase induction motor in program Ansys Maxwell (transient mode) [22], [23]. By designing the motor and entering the data of curves into the program after applying the type of steel and obtained the results of iron core losses with copper losses and assessment the performance of the motor in each type of steel.

\section{DESIGN OF THREE PHASE INDUCTION MOTOR}

The three-phase induction motor is designed in the Maxwell program using RMxprt that used a set of analytical and magnetic circuit equations to perform a more detailed analysis and more accurate performance forecasts. The general data of the motor characteristics are listed in Table 1:

Table 1. Parameters and specifications for three phase induction motor

\begin{tabular}{lc}
\hline Parameters and specifications & Value \\
\hline RMS line-to-line rated voltage & $460 \mathrm{~V}$ \\
Frequency & $60 \mathrm{~Hz}$ \\
Rated speed & $3502 \mathrm{RPM}$ \\
Iron core length & 9.5 inches \\
Stacking factor & 0.95 \\
Number of stator slots & 36 \\
Inner diameter of stator & 5.525 inches \\
Outer diameter of stator & 10.125 inches \\
Number of rotor slots & 28 \\
Outer diameter of rotor & 5.479 inches \\
Inner diameter of rotor & 1.875 inches \\
Air gap & 0.046 inches \\
Number of conductor & 11 \\
Resistance for phase winding & 3.9234 ohm \\
Inductance for phase winding & $0.000561606 \mathrm{H}$ \\
Number of parallel branches & 1 \\
\hline
\end{tabular}

The shapes of slots for stator and rotor as shown in Figure 1 and Figure 2. The dimensions of slot for stator and rotor as shown in Table 2.

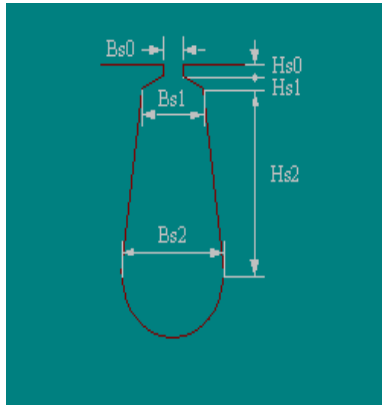

Figure 1. The shape of slot for stator

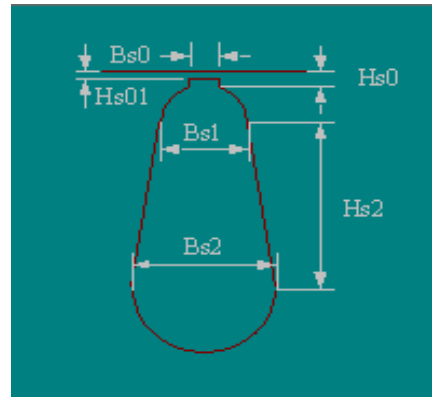

Figure 2. The shape of slot for rotor

Table 2. The dimensions of slot for stator and rotor for three phase induction motor

\begin{tabular}{llll}
\hline \multicolumn{2}{l}{ dimensions of stator slots } & \multicolumn{2}{c}{ dimensions of rotor slots } \\
\hline Hs0 & 0.0550 inches & Hs0 & 0.0215 inches \\
Hs1 & 0.0650 inches & Hs01 & 0.0100 inches \\
Hs2 & 0.6980 inches & Hs2 & 0.2200 inches \\
Bs0 & 0.1600 inches & Bs0 & 0.0100 inches \\
Bs1 & 0.3090 inches & Bs1 & 0.1500 inches \\
Bs2 & 0.4320 inches & Bs2 & 0.1600 inches \\
\hline
\end{tabular}


The design of three phase induction motor is shown in the Figure 3.

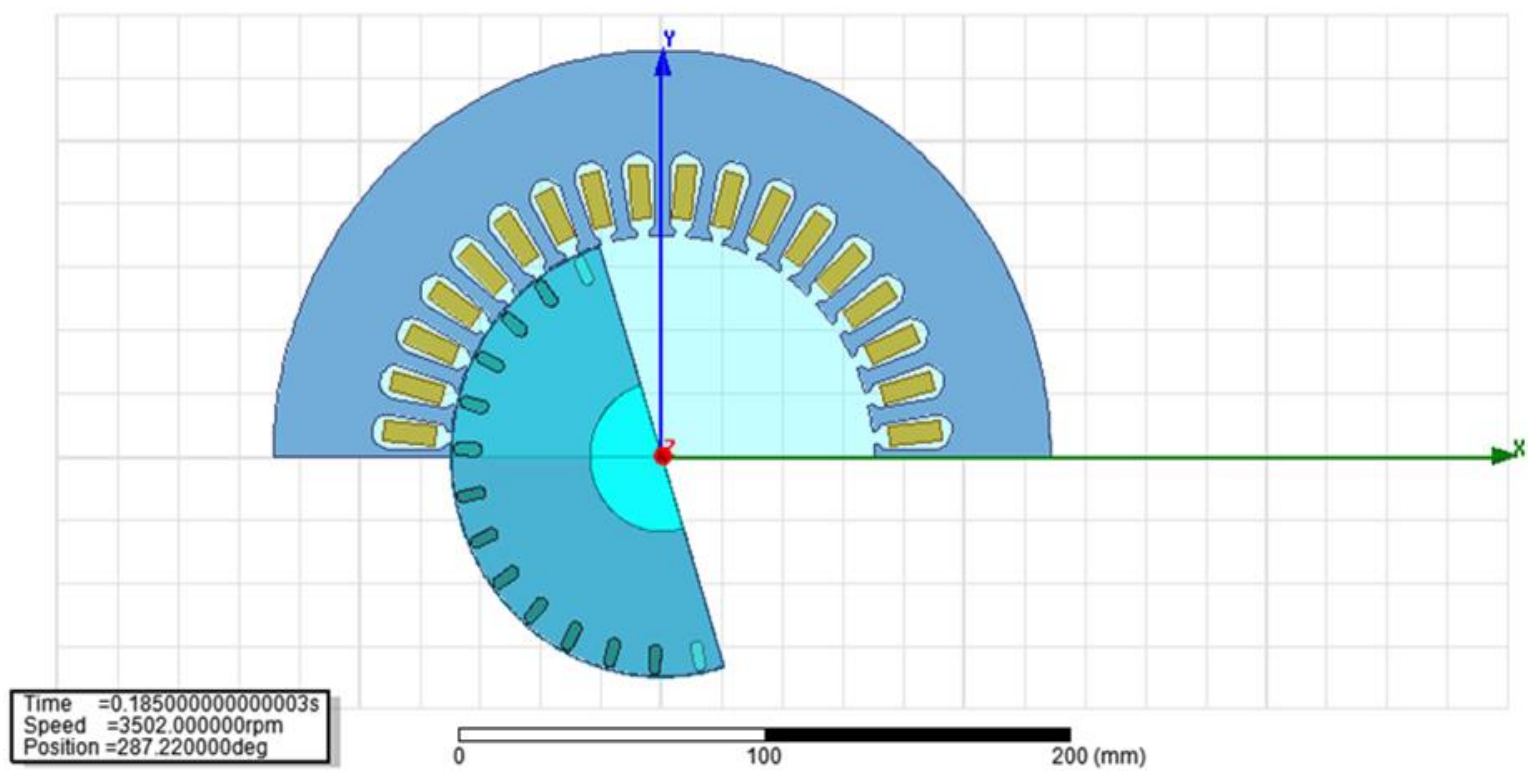

Figure 3. The design of three phase induction motor

For the calculating purpose of core losses, the proposed material properties must be applied in the design of stator and rotor for motor core, while the aluminum material is used in the bars and the end ring of bars for motor rotor [24], [25]. In the first case, Cobalt steel type (Hiperco 50) has been used as a core material. Figure 4 shows the magnetization curve $(B-H)$ for Cobalt steel (Hiperco 50). Figure 5 shows the specific core losses curve that obtained by using Cobalt steel (Hiperco 50) at frequency $(f=60 \mathrm{~Hz})$ and the thickness of steel sheet equals $t=0.635 \mathrm{~mm}$.

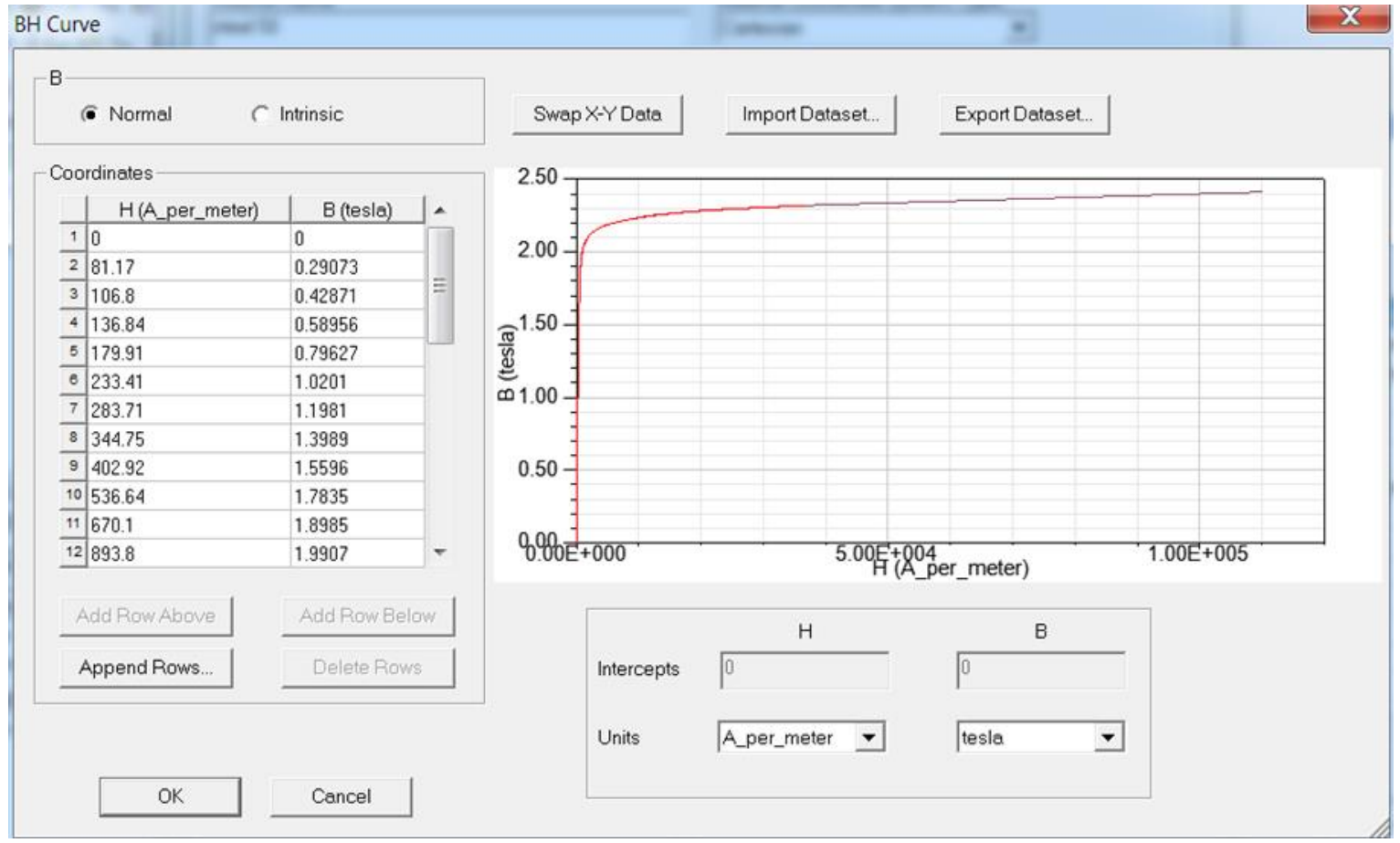

Figure 4. The magnetization curve $(B-H)$ for cobalt steel (hiperco 50) 


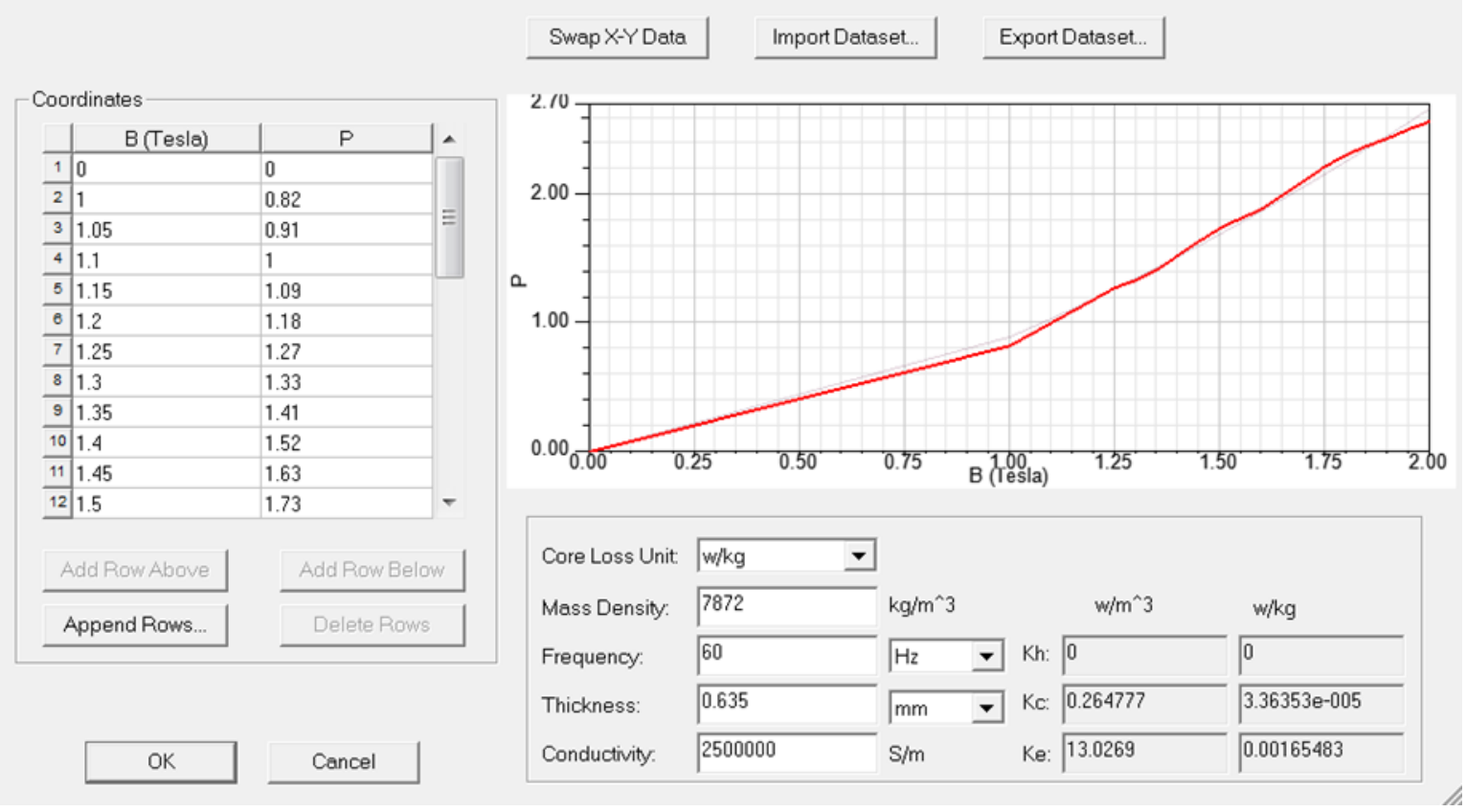

Figure 5. The core losses curve that obtained by using cobalt steel (hiperco 50)

In the second case, Electrical Steel - Non Grain Oriented type (NGO type AK Steel's M-19) has been used as a core material. Figure 6 shows the magnetization curve $(B-H)$ for Electrical Steel NGO-AK Steel's M-19. Figure 7 shows the specific core losses curve that obtained by using Electrical Steel NGO-AK Steel's M-19 at frequency $(f=60 \mathrm{~Hz})$ and the thickness of steel sheet equals $t=0.635 \mathrm{~mm}$.

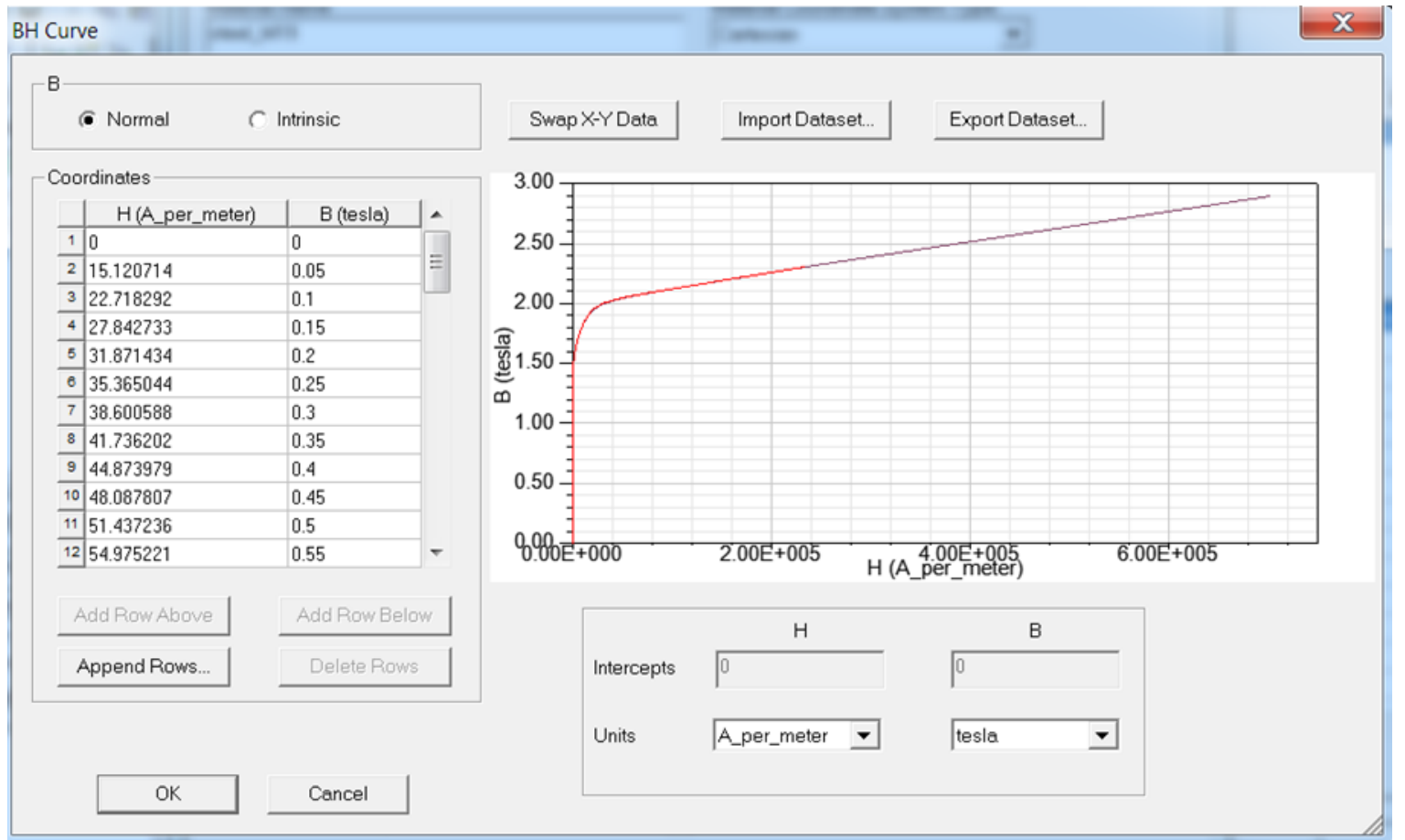

Figure 6. The magnetization curve $(B-H)$ for electrical steel NGO-AK steel's M-19 


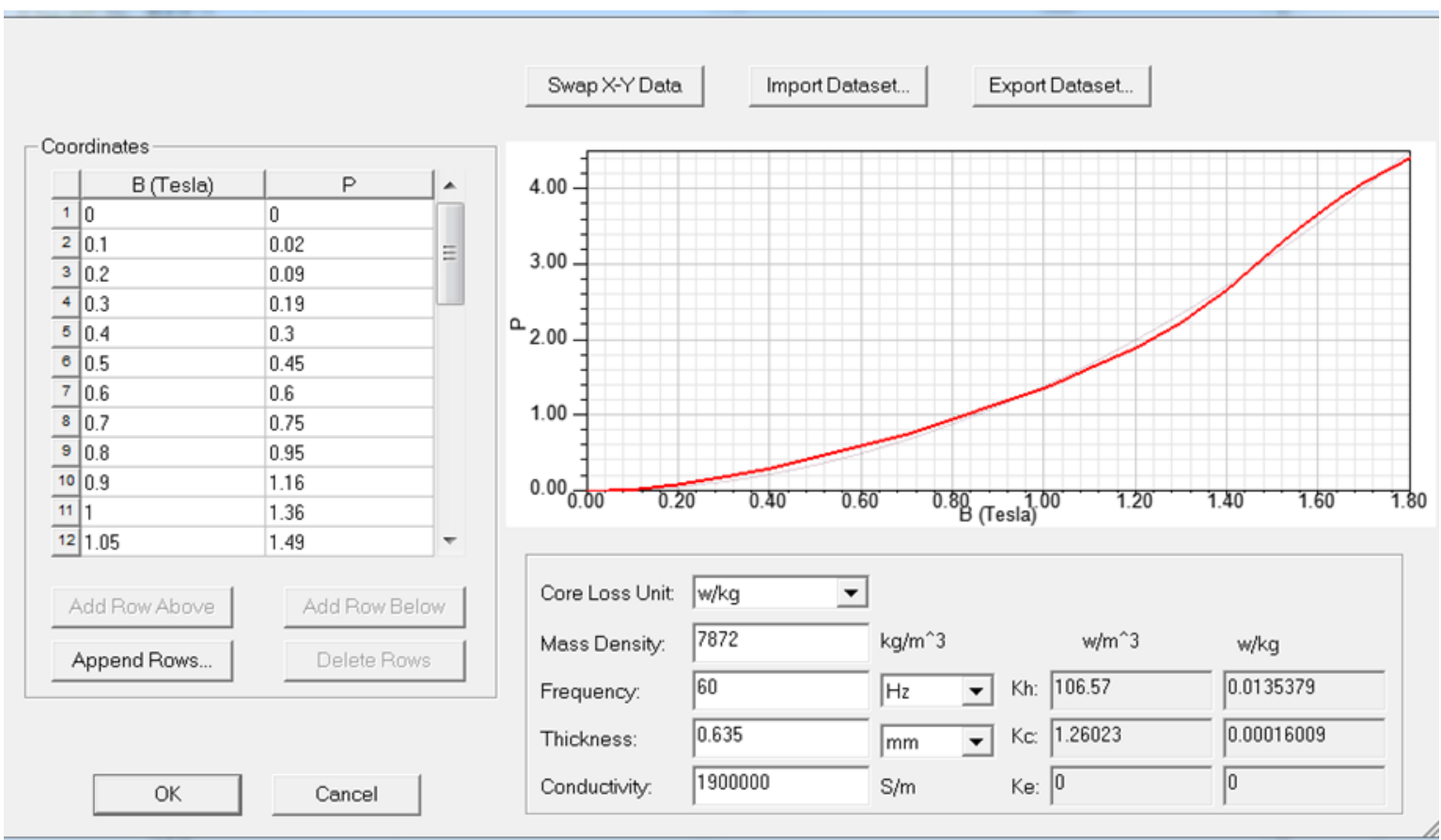

Figure 7. The core losses curve that obtained by using electrical steel NGO-AK steel's M-19

In the third case, Low Carbon Steel-SAE1020 has been used as a core material. Figure 8 shows the magnetization curve $(B-H)$ for Low Carbon Steel-SAE1020. Figure 9 shows the specific core losses curve that obtained by using Low Carbon Steel-SAE1020 at frequency $(f=60 \mathrm{~Hz})$ and the thickness of steel sheet equals $t=0.635 \mathrm{~mm}$.

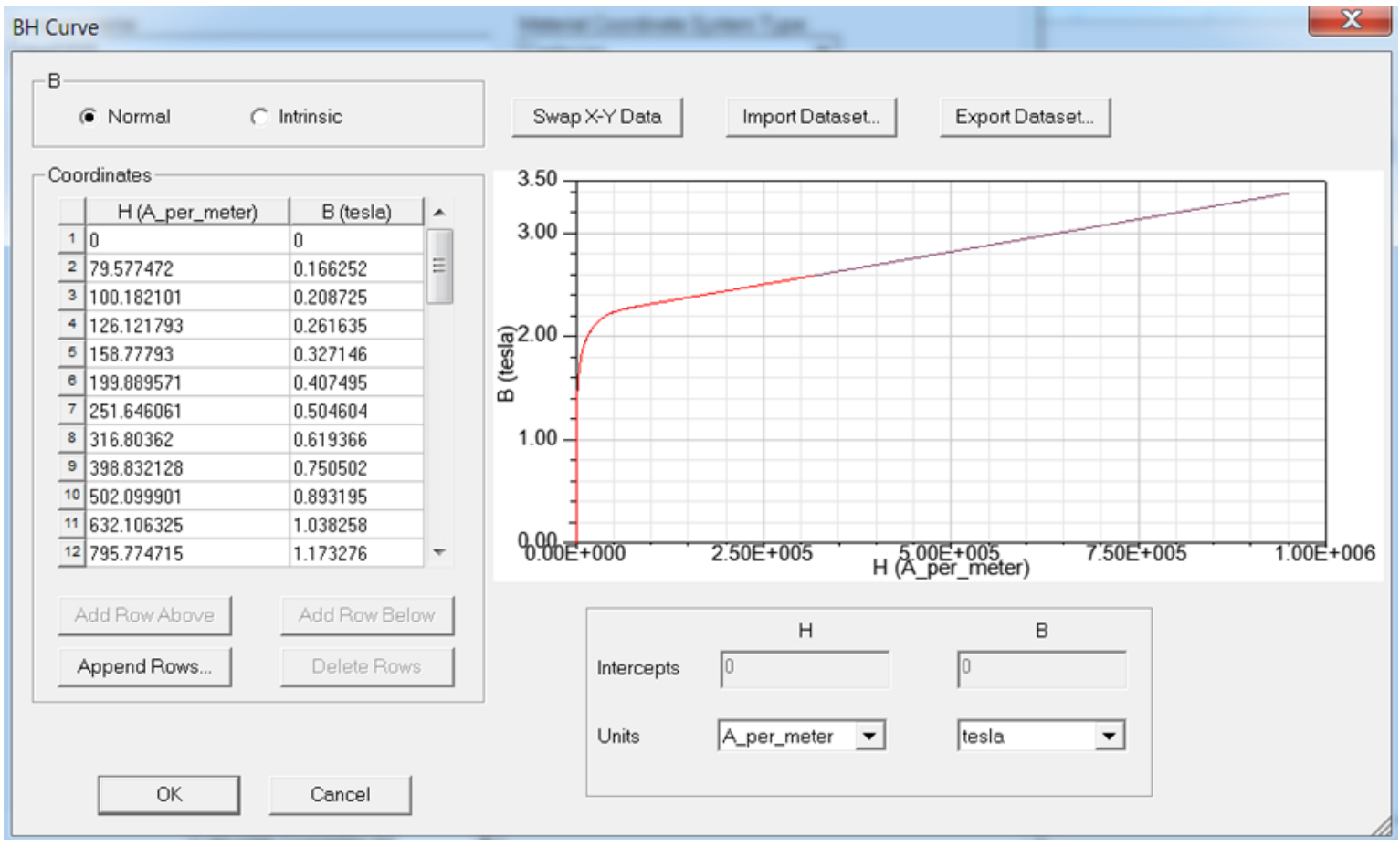

Figure 8. The magnetization curve $(B-H)$ for low carbon steel-SAE1020 


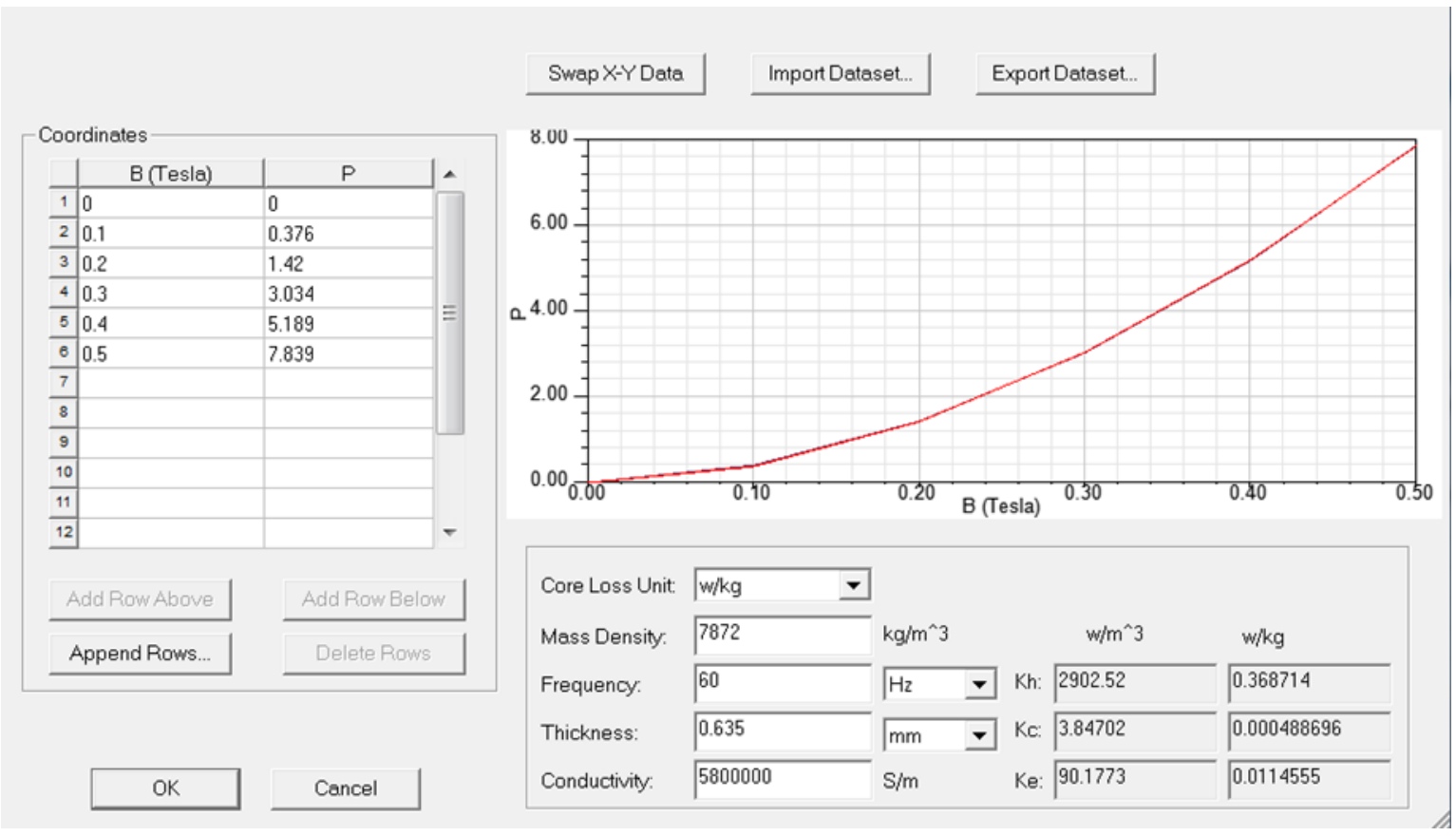

Figure 9. The core losses curve that obtained by using low carbon steel-SAE1020

From Figures 5, 7 and 9 it is clear that the program calculates all the coefficients of iron losses $K_{c}$, $K_{h}$ and $K_{e}$ for three cases.

\section{RESULTS OF CORE LOSSES AND PERFORMANCE CHARACTERISTICS}

In this section, the ability of the proposed three types of steel materials for core design of a threephase induction motor in losses reduction and efficiency improvement are investigated. The motor is operated with each one of the proposed steel materials for no load condition and transient mode to obtain the results of core losses and check the effectiveness of these steel materials. Figure 10 shows the magnetic field distribution lines in the motor using Cobalt steel (Hiperco 50).

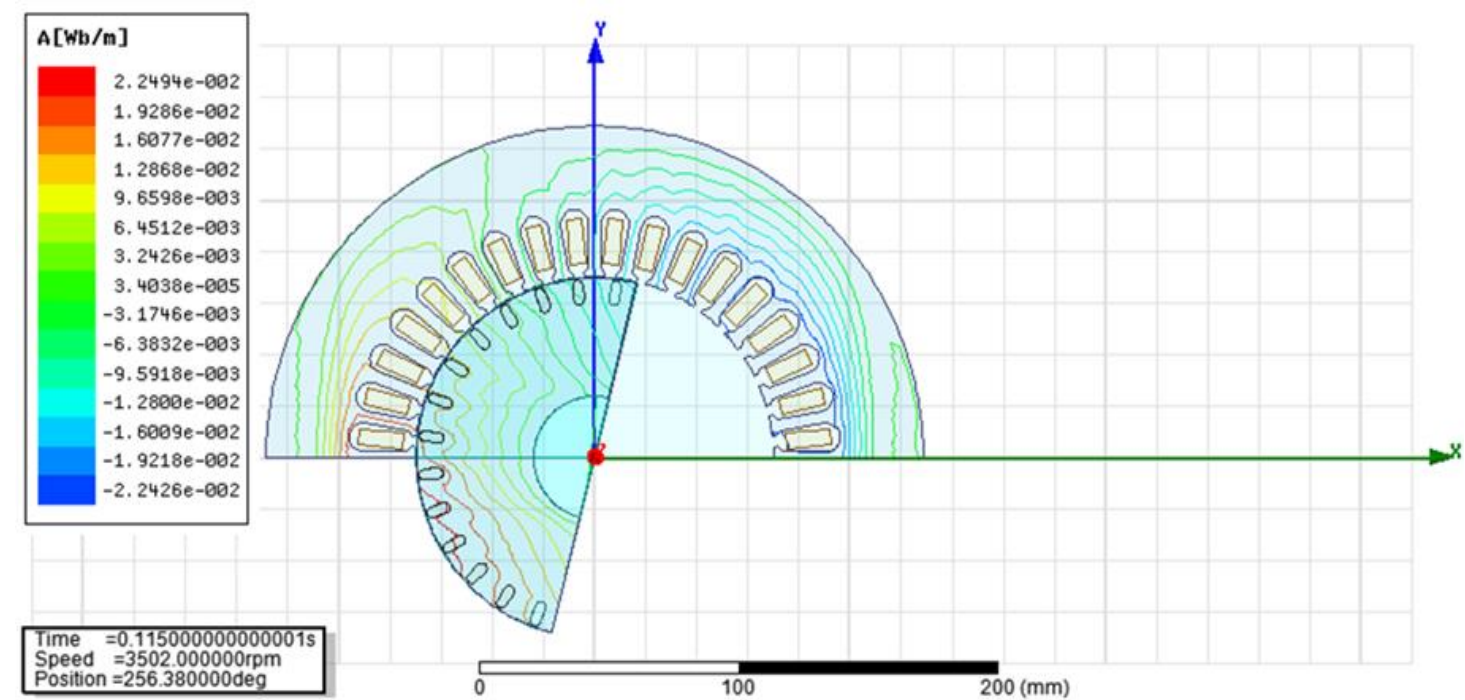

Figure 10. Magnetic field distribution lines in the motor using cobalt steel (hiperco 50) 
Figures 11 and 12 show the voltage of source and the current consuming in the stator winding.

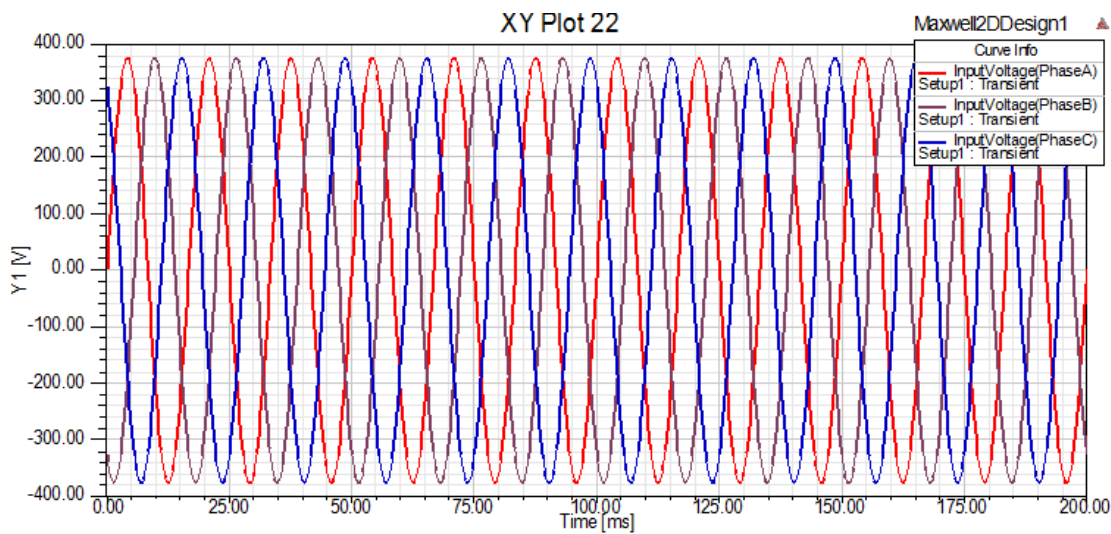

Figure 11. The input voltage of source

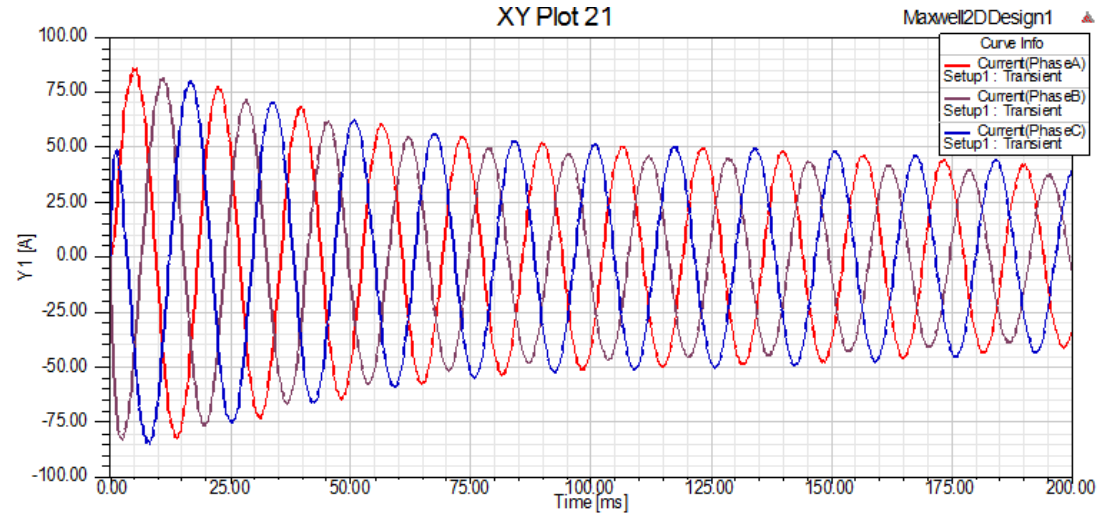

Figure 12. The current consuming in the stator winding

Figures 13, 14 and 15 show the results of core losses curve for the proposed three types of steel materials.

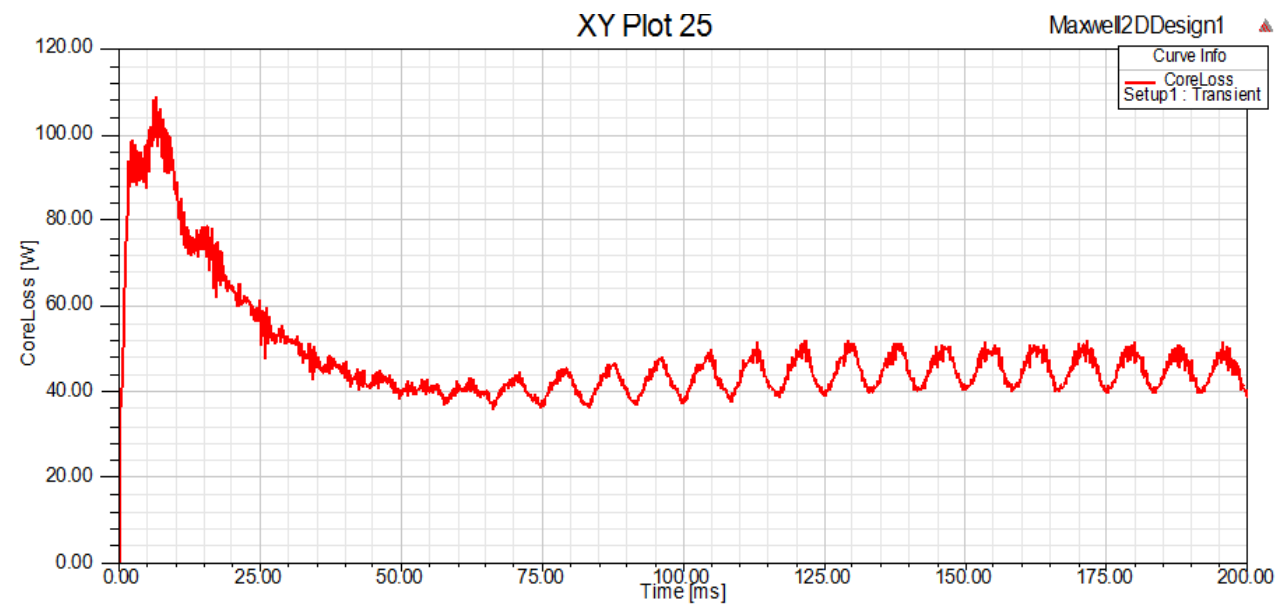

Figure 13. Core losses curve for cobalt steel (hiperco 50) 


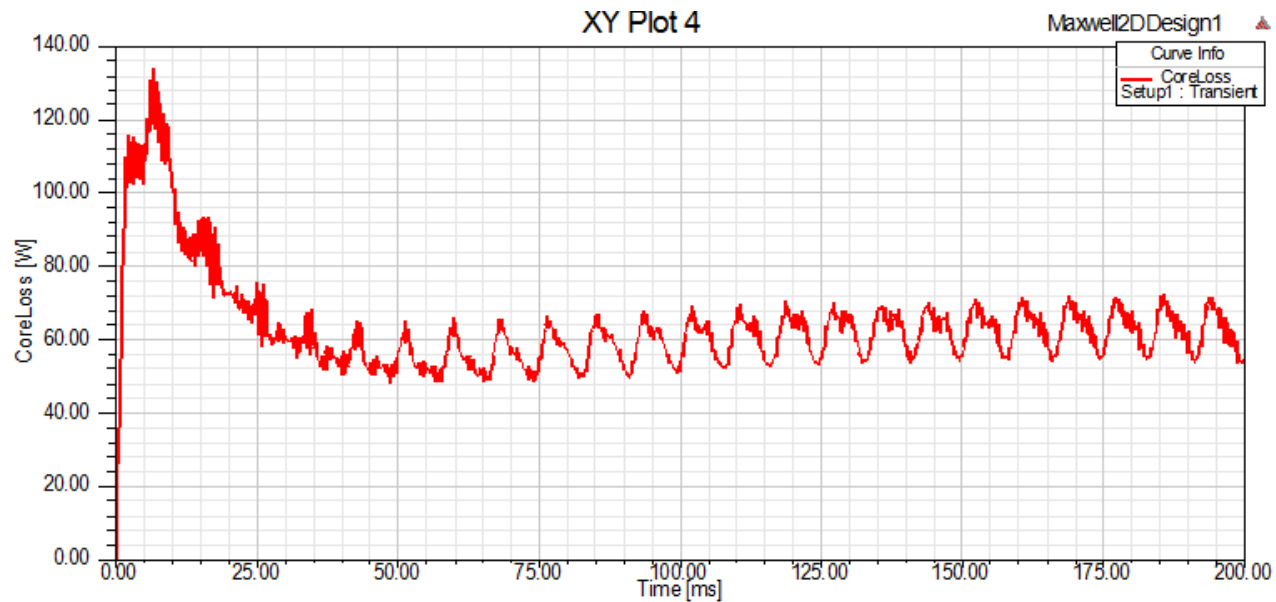

Figure 14. Core loss curve for electrical steel NGO-AK steel's M-19

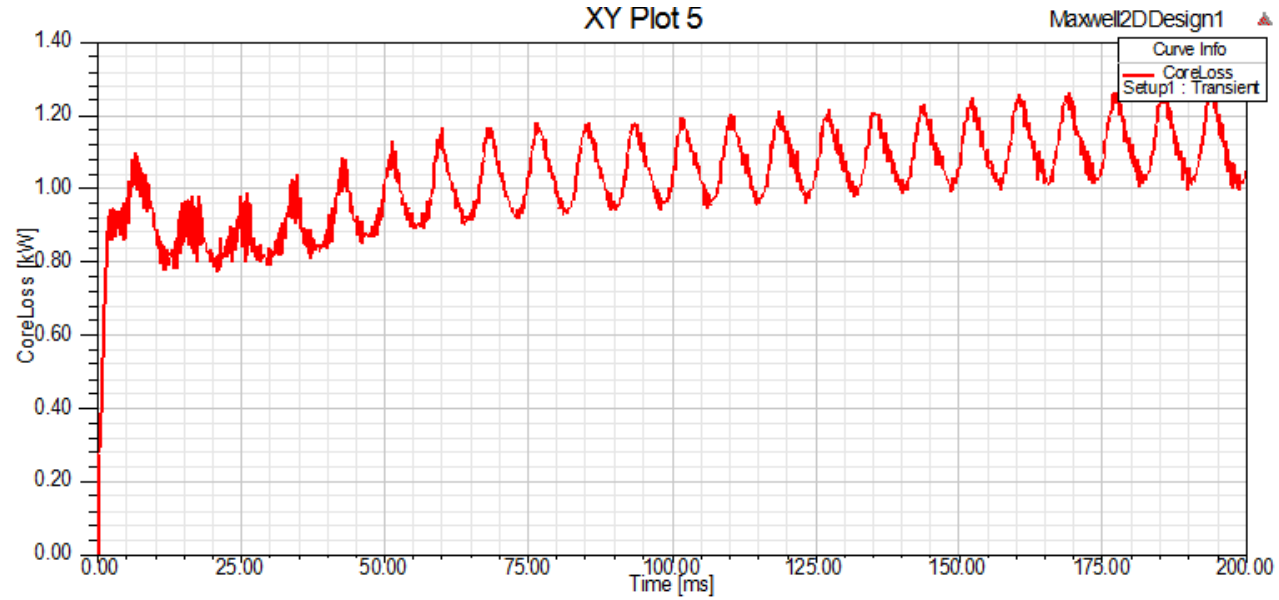

Figure 15. Core loss curve for low carbon steel-SAE1020

Figures 16, 17 and 18 show the results of copper losses curve in the stator windings for the proposed three types of steel materials.

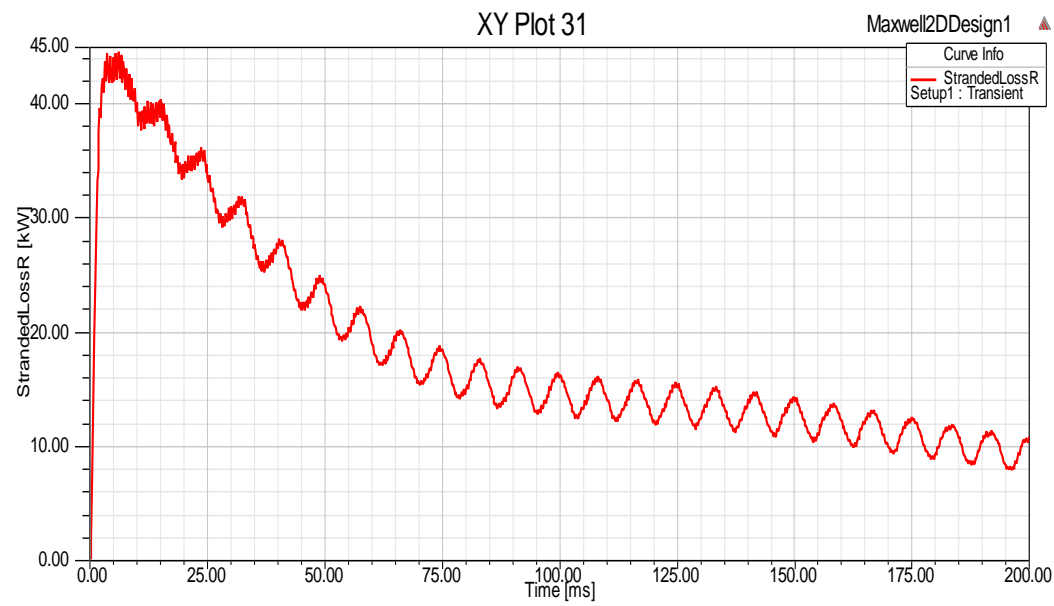

Figure 16. Copper loss for (hiperco 50) 


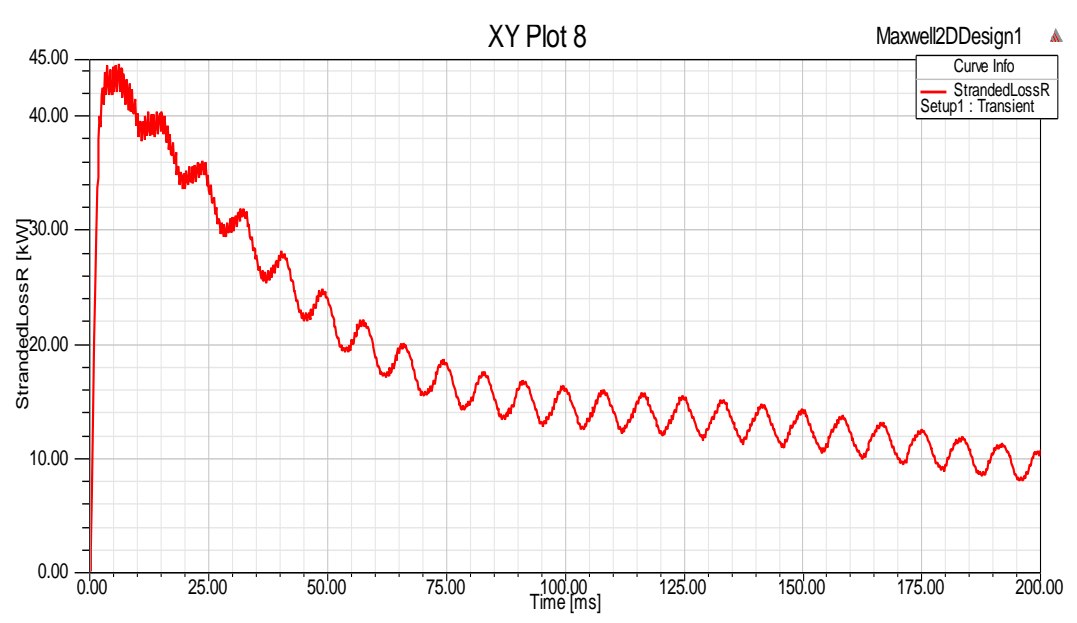

Figure 17. Copper loss for M-19

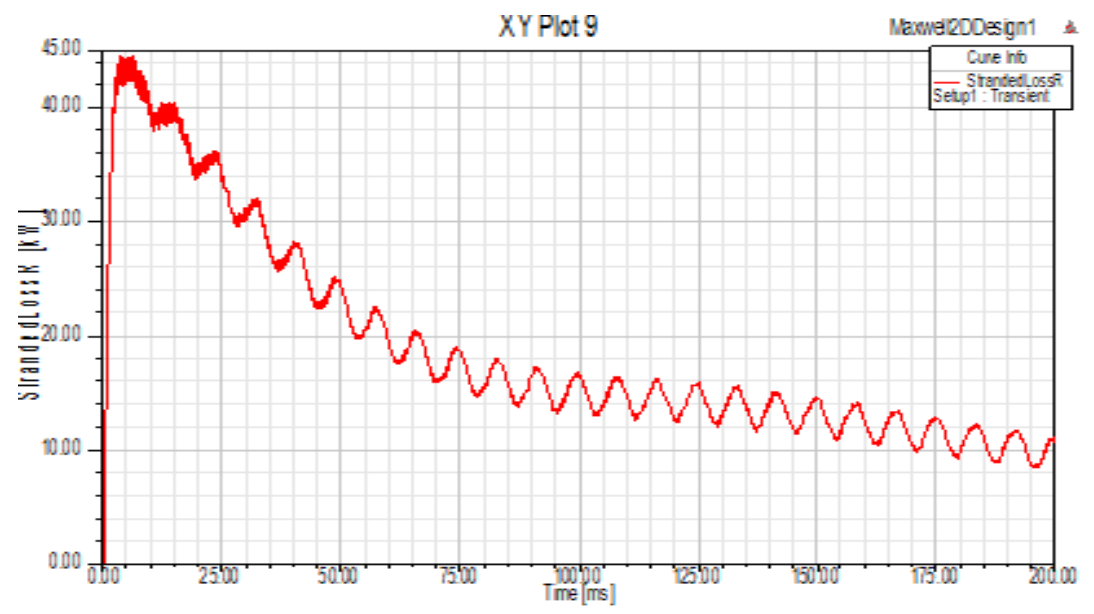

Figure 18. Copper loss for steel-SAE1020

It can be seen from the results of Core loss curves that the better performance is obtained by using the Cobalt steel (Hiperco 50) material, which has the lower absolute value for average core losses curve (48.409 W) than the Electrical Steel NGO-AK Steel's M-19 (63.887 W) and Low Carbon Steel-SAE1020 $(1027.873 \mathrm{~W})$. The superiority of proposed Cobalt steel (Hiperco 50) is due to the efficiency of magnetic properties of this material.

\section{CONCLUSION}

This paper proposed a three type of steel materials in the core design for three-phase induction motor by using "ANSYS Maxwell" program which supported the calculation of core loss and copper loss depend on coefficients that are calculated based on the data of loss curves. It is necessary to know the specific core losses for each type of steel material in order to identify the best type that provides the lowest core losses. From the results demonstrated that Cobalt steel (Hiperco 50) representing the better choice in comparison with other types of steel materials in terms of less core losses. Also, the results show that the copper losses not affecting by type of core material.

\section{REFERENCES}

[1] M. B. B. Sharifian et al., "Torque Fluctuations Reducing in a Vector Controlled Motor Drive by PI Controller Tuning Using Particle Swarm Optimization," 2011 International Conference on Electrical Machines and Systems, 2011, pp. 1-6. 
[2] A. Chourasia1 et al., "Comparison Study of Vector Control of Induction Motor Using Rotor Flux Estimation by Two Different Methods," International Journal of Electronic and Electrical Engineering, vol. 7, pp. 201-206, 2014.

[3] S. H. Asgari, M. Jannati, T. Sutikno, and N. R. N. Idris, "Vector Control of Three-Phase Induction Motor with Two Stator Phases Open-Circuit," International Journal of Power Electronics and Drive System (IJPEDS), vol. 6, pp. 282-292, 2015.

[4] M. Jannati, T. Sutikno, N. R. N. Idris, and M. J. A. Aziz, "A Novel Method for IRFOC of Three-Phase Induction Motor under Open-Phase Fault," International Journal of Power Electronics and Drive System (IJPEDS), vol. 6 , pp. 439-448, 2015.

[5] T. Hambissa, "Analysis and DSP Implementation of Sensor-Less Direct FOC of Three-Phase Induction Motor Using Open-Loop Speed Estimator," School of Electrical and Computer Engineering, Addis Ababa Institute of Technology , Addis Ababa University, Addis Ababa, Ethiopia, M.Sc. thesis, May, 2017.

[6] M. Jannatil and T. Sutikno, "Modelling of a 3-phase Induction Motor under Open-phase Fault Using Matlab/Simulink," International Journal of Power Electronics and Drive System (IJPEDS), vol. 7, pp. 1146-1152, 2016.

[7] G. V. V. Nagaraju and G. S. Rao, "Three phase PUC5 inverter fed induction motor for renewable energy applications," International Journal of Power Electronics and Drive System (IJPEDS), vol. 11 , pp. 1-9, 2020.

[8] M. M. Elkholy and M. A. Elhameed, "Minimization of Starting Energy Loss of Three Phase Induction Motors based on Particle Swarm Optimization and Neuro Fuzzy Network," International Journal of Power Electronics and Drive System (IJPEDS), vol. 7, pp. 1038-1048, 2016.

[9] Abdulrahim et al., "Direct Torque Control of Induction Motor Based on Particle Swarm Optimization," Journal of Al Rafidain University College, vol. 10, pp. 1506-1513, 2013.

[10] J. Kartigeyan et al., "Magnetic Materials for Rotating Electrical Machines: A Selection Perspective," International Journal of Applied Engineering Research, vol. 13, pp. 87-108, 2018.

[11] G. Singh et al., "Computational Design and Analysis of Core Material of Single-Phase Capacitor Run Induction Motor," Journal of Engineering Research and Applications, vol. 4, pp. 20-25, Jul. 2014.

[12] O. Tikhonova et al., "Loss calculation of induction motor with ring windings by ANSYS MAXWELL," in IEEE Conference of Russian Young Researchers in Electrical and Electronic Engineering, 2017, pp. 63-66.

[13] R. N. F. R. Othman, F. Sulaiman, S. Rizuan, K. A. Karim, A. Jidin, T. Sutikno, and N. Misron, "Design of HollowRotor Brushless DC Motor," International Journal of Power Electronics and Drive System (IJPEDS), vol. 7, pp. 387-396, 2016.

[14] M. Jannati, S. Eskandari, and T. Sutikno, "Speed Control of 3-phase Induction Motors under Fault Conditions Supplied by Wind Turbine Using Indirect Vector Control," International Journal of Power Electronics and Drive System (IJPEDS), vol. 8, pp. 222-230, 2017.

[15] S. Shrinivetha et al., "Direct Torque Controlled Induction Motor Drive Using Ansys Maxwell Simplorer," International Journal of Engineering Research in Electrical and Electronic Engineering (IJEREEE), vol. 4, pp. 42-44, 2018.

[16] D. M. Ionel, "Computation of Core Losses in Electrical MachinesUsing Improved Models for Laminated Steel," IEEE Transactions on Industry Applications, vol. 43, pp. 1554-1564, 2007.

[17] N. A. M. Yusoff, K. A. Karim, S. A. Ghani, T. Sutikno, and A. Jidin, "Multiphase Transformer Modelling using Finite Element Method," International Journal of Power Electronics and Drive System (IJPEDS), vol. 6, pp. 56-64, 2015

[18] M. M. Elkholy and M. A. Elhameed, "Braking of Three Phase Induction Motorsby Controlling Applied Voltage and Frequency Based on Particle Swarm Optimization Technique," International Journal of Power Electronics and Drive System (IJPEDS), vol. 5, pp. 520-528, 2015.

[19] D. K. Rao et al., "MagWeb Database of Soft Magnetic Materials," MagWeb, USA, pp. 6-9, 2019.

[20] B. K. Vipinchandra et al., "Electromagnetic analysis of Induction motor using FEM," Journal of Emerging Technologies and Innovative Research, vol. 1, pp. 903-908, 2014.

[21] S. Tumanski, "Handbook of Magnetic Measurements," CRC Press, pp. 126-129, 2011.

[22] E. C. Abunike et al., "Steady and Dynamic States Analysis of Induction Motor: Fea Approach," Nigerian Journal of Technology, vol. 36, pp. 1202-1207, 2017.

[23] Y. Bensalem et al., "Modeling and Simulation of Induction Motor based on Finite Element Analysis," International Journal of Power Electronics and Drive System, vol. 7, pp. 1100-1109, 2016.

[24] A. M. Takbash et al., "Losses Characterization in Voltage-Fed PWM Inverter Induction Motor Drives Under Rotor Broken Bars Fault," IEEE Transactions on Magnetics, vol. 49, pp. 1516-1525, 2013.

[25] T. Vaimann et al., "Changing of Magnetic Flux Density Distribution in a Squirrel-Cage Induction Motor with Broken Rotor Bars,” Elektronika ir Elektrotechnika, vol. 20, pp. 11-14, 2014. 


\section{BIOGRAPHIES OF AUTHORS}

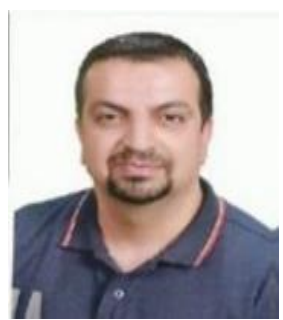

Yaser Atta Yassin was born in Iraq on June 24, 1976. He recived his B. Sc from Al Mustansiriyah University/Iraq 1999 from College of Engineering-Department of Electrical Engineering. M.Sc from National Research University/Moscow Power Engineering Institute/Russia/2017. He is currently Assist Lecturer in Dept. of Electrical Power Technical Engineering/Electrical Engineering Technical College/Middle Technical University.

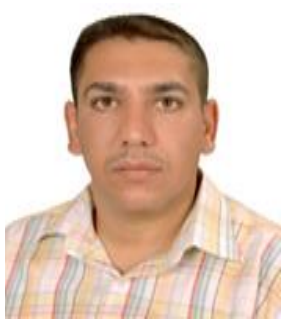

Ali Nasser Hussain was born in Iraq on April 30, 1974. He received his B.Sc. and M.Sc. in Electrical \& Electronics Engineering, University of Technology, Baghdad, Iraq, in 1998 and in 2005 respectively and his $\mathrm{PhD}$ degrees in Electrical Engineering from University Malaysia Perlis (UniMAP), Perlis, Malaysia in 2014. Since 2004 he is a senior lecturer in the Electrical Engineering Technical College at Middle Technical University. His current research interests include power system operation and control, electrical power system stability and intelligent optimization, renewable energy, robust control.

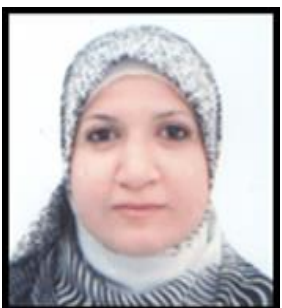

Nagham Yassin Ahmed: was born in Baghdad in 1976. She had awarded the B.Sc. degree from the department of physics, College of Science for Women, University of Baghdad in the year 1997/1998. M.Sc in the Department of Physics, College of Science for Women, University of Baghdad 2015. She is currently Assistant lecturer in Dept. of Department of Medical Instrumentation Techniques Engineering/Electrical Engineering Technical College/Middle Technical University. 